\title{
Indoor Daylight Spectral Characteristics and Illuminance Levels Measurements in Deep Space Rooms and its Evaluation for Human Visual and Biological Response
}

\begin{abstract}
Slovak standards and regulations for design and evaluation of indoor daylight in residential buildings require average values of the Daylight Factor $(D)$ in two check points as basic criterion. In offices, the daylighting is evaluated in workplaces which can be often situated far from window. In this paper are presented results of daylighting measurements in deeper positions in three model rooms with different internal coloured surfaces which are exposed only to natural daylight during cloudy days. Positions are investigated from point of view of visual and biological response performance, represented by circadian efficiency, which may be significantly influenced by indoor surface's colour selection.
\end{abstract}

Keywords: Daylight Factor, daylight spectral characteristics, spectral reflectance, circadian system, experiment in situ, colour rendering index

\section{Introduction}

The significance of biological effect of light on human behaviour, also known as circadian efficiency of light became frequently discussed issue during last decade. There is already a fact confirmed, that biological stimulation demands more complex requirements than visual perception. In addition, biological stimulation is invoked by light, which penetrates into retina, so in position of sitting person, the vertical plane in the height of eyes should be evaluated. The parameters, which have the most powerful effect on human biological response, are illuminance level, spectral composition, distribution, timing and duration of light exposure [1]. Prior experiments taken to monitor biological response related with measuring of concentration of melatonin - the sleep hormone discovered the presence of non-visual photoreceptor called ipRGC (intrinsically photosensitive Retinal Ganglion Cells) [2-3]. The ipRGC is the most sensitive in blue light spectrum and has presumably no visual function, but ipRGC has crucial influence on biological stimulation [4-5]. Control of melatonin regulation during 24 hours is considered to be one of the most important factors for our behaviour and wellbeing [6]. On the basis of melatonin suppression, the circadian photoreception curve $C_{\lambda}$ was established. The curve represents biological equivalent to luminous efficiency curve $V_{\lambda}$. Natural daylight dominates in blue region is the most effective light source for control of our biological response. Calculation method, which is used for determination of biological stimulation efficiency provided by ambient light, was defined. Rea [4] suggested methodology which includes:

$C L_{A}-$ normalized circadian light in "circadian lux" [ $\left[\mathrm{x}_{\mathrm{C}}\right]$

$C S$ - circadian stimulus [ -$]$

$C L_{A}$ can be regarded as biological equivalent to photopic illuminance and $C S$ is dimensionless unit and represents the rate effect of light conditions for melatonin suppression. Mathematical model allows achievement of max value 0.75 . Healthy melatonin concentration stays at minimum levels during day and continual rising as dark comes with peak during night. Therefore it is desired to be exposed to light, which provides $C S$ close to 0.75 during day and $C S$ close to 0 during night.

Actual indoor daylight regulations are focused on illuminance level measured on horizontal plane. The paper deals with experimental measuring on three models of deep office room intended for permanent workplace and exposed only to natural daylight. During the experiment, photopic illuminance and Daylight Factor levels on horizontal plane were measured in three positions considering the distance from window. In addition, modifications in internal daylight spectrum were monitored in six positions. These changes in spectrum were caused by the colour of internal surfaces. Spectral characteristics were measured on vertical plane in the height of sitting person's eyes and subsequently the values were evaluated for its potential biological response according calculation method defined by Rea [4].

\section{Description of experiment}

Three model rooms designed in scale 1:5 were situated on the rooftop of Slovak University of Technology, Faculty of Civil Engineering in Bratislava, Slovakia, Fig. 1. The experiment was done in real conditions on April $7^{\text {th }}, 2015$ at 01:00 PM. It was cloudy.

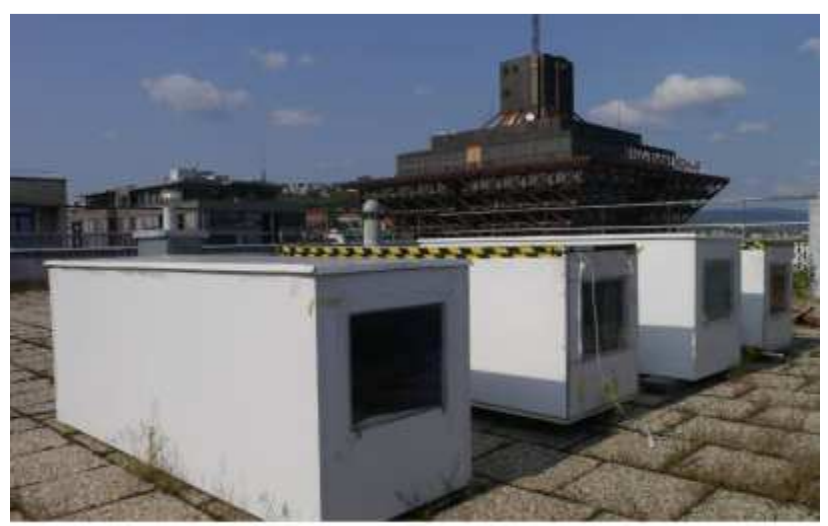

Fig. 1. View of models on flat roof, during preparation, exposed to daylight

All models were exposed to natural daylight without any additional light source. The room models dimensions are $600 \mathrm{~mm} \times 600 \mathrm{~mm} \times 2000 \mathrm{~mm}$, which represent $3 \mathrm{~m} \times 3 \mathrm{~m}$ $\times 10 \mathrm{~m}$. The window opening with single glazing was 420 $\mathrm{mm} \times 300 \mathrm{~mm}$, which represents $2.1 \mathrm{~m} \times 1.5 \mathrm{~m}$ with window sill in $170 \mathrm{~mm}$ or $0.85 \mathrm{~m}$ above floor in real, Fig. 2 . 


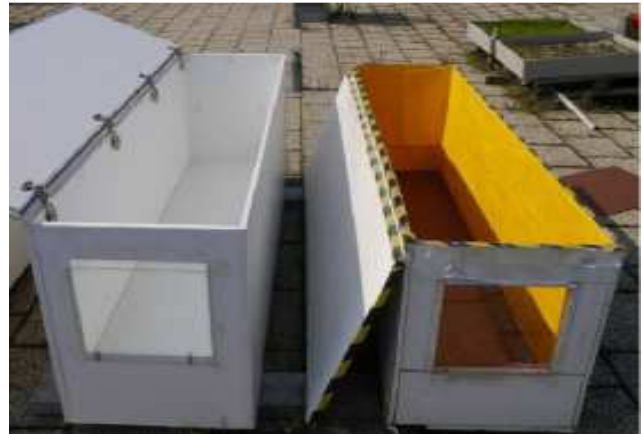

Fig. 2. View on internal surface`s design

The coloured wallpapers were applied to internal surfaces as follow: i) the reference room model remained with all surfaces in original white colour; ii) there was brown flooring and white ceiling in other two tested models; iii) the second room model was equipped by orange walls and the third room by yellow walls, Fig. 3. Photopic illuminance levels were evaluated on horizontal plane in three room depth positions $-600 \mathrm{~mm}, 1200 \mathrm{~mm}$ and $1600 \mathrm{~mm}$. In the same positions, there were evaluated spectral characteristics on vertical plane in the height of $240 \mathrm{~mm}$ (or $1.2 \mathrm{~m}$ above room floor) with direction of sensor to window and to side wall, Fig. 2.



Fig. 3. Longitudinal section of reference / tested models

\section{Measuring instruments}

Spectrophotometer Konica Minolta CM-5 was used for evaluation of surface's spectral reflectance in Tab. 1. Photopic illuminance on horizontal plane and spectral characteristics of daylight on vertical plane were evaluated by spectrophotometer Konica Minolta CL 500A.

\section{Results}

The internal surface's spectral reflectance values are documented in Fig. 4. According (1-2), absolute reflectance counted by $V_{\lambda}$ and $C_{\lambda}$ are showed in Tab. 1 .

(1)

$$
\rho_{V}=\frac{\sum_{\lambda=380 \mathrm{~nm}}^{\lambda=780 \mathrm{~nm}} D_{\lambda} \rho_{(\lambda)} V_{(\lambda)} \Delta_{\lambda}}{\sum_{\lambda=380 \mathrm{~nm} m}^{\lambda} D_{\lambda} V_{(\lambda)} \Delta_{\lambda}} \quad \text { (2) } \rho_{c}=\frac{\sum_{\lambda=380 \mathrm{~nm}}^{\lambda=580 \mathrm{~nm}} D_{\lambda} \rho_{(\lambda)} C_{(\lambda)} \Delta_{\lambda}}{\sum_{\lambda=380 \mathrm{~nm}} D_{\lambda} C_{(\lambda)} \Delta_{\lambda}}
$$

where: $\rho_{(\lambda)}-$ measured spectral reflectance $\left[\left(\mathrm{W} / \mathrm{m}^{2}\right) / \mathrm{nm}\right]$, $D_{(\lambda)}-$ spectral composition of $D_{65}\left[\left(\mathrm{~W} / \mathrm{m}^{2}\right) / \mathrm{nm}\right]$, $\Delta_{(\lambda)}$ - elementary wavelength [nm], $\rho_{V}, \rho_{C}-$ absolute photopic/circadian reflectance of samples [-].



$-V(\lambda)$ - luminous efficiency curve $\cdots C(\lambda)$ - circadian photoreception

-orange wallpaper $\quad$-yellow wallpaper

- dark brown flooring - - reference white surface

Fig. 4. Spectral reflectance of samples measured by $\mathrm{CM}-5$

Table 1. The results of absolute surface's reflectance

\begin{tabular}{|c|c|c|c|}
\hline Sample & $\begin{array}{c}\text { Colour of } \\
\text { surface }\end{array}$ & $\rho_{\sqrt{ }[-]}$ & $\rho_{C}[-]$ \\
\hline reference & & 0.72 & 0.75 \\
\hline dark brown & & 0.12 & 0.07 \\
\hline yellow & & 0.65 & 0.17 \\
\hline orange & & 0.27 & 0.06 \\
\hline
\end{tabular}

Table 2. Horizontal photopic illuminance levels $E_{v}$ and Daylight

\begin{tabular}{|c|c|c|c|c|c|c|c|c|c|}
\hline Position & \multirow{5}{*}{$\begin{array}{l}\bar{\Phi} \\
\frac{0}{0} \\
\text { E }\end{array}$} & $E_{v}$ & $D$ & \multirow{5}{*}{$\begin{array}{l}\bar{\Phi} \\
\bar{D} \\
\underline{E}\end{array}$} & $E_{v}$ & $D$ & \multirow{5}{*}{$\begin{array}{l}\bar{\Phi} \\
\frac{0}{0} \\
\text { E }\end{array}$} & $E_{v}$ & $D$ \\
\hline $\begin{array}{c}\text { from } \\
\text { window }\end{array}$ & & {$[\mathrm{lx}]$} & {$[\%]$} & & {$[\mathrm{lx}]$} & {$[\%]$} & & {$[\mathrm{lx}]$} & [\%] \\
\hline $600 \mathrm{~mm}$ & & 369 & 3.1 & & 738 & 6.1 & & 340 & 2.8 \\
\hline $1200 \mathrm{~mm}$ & & 110 & 0.9 & & 381 & 3.2 & & 128 & 1.1 \\
\hline $1600 \mathrm{~mm}$ & & 72 & 0.6 & & 271 & 2.2 & & 63 & 0.5 \\
\hline \multicolumn{7}{|c|}{ External photopic illuminance level $E_{v}$} & \multicolumn{3}{|c|}{$11940 \mathrm{~lx}$} \\
\hline
\end{tabular}
Factor levels $D F$

The effect of coloured surfaces in models caused noticeable difference in vertical illuminance, which was decreasing with raising measured position in depth of the room model. In position $600 \mathrm{~mm}$ from window, the $E_{v}$ levels reached value $738 \mathrm{Ix}$ in reference model, whereas both coloured model provided one half of this amount. With raising distance from the window the effect of colour selection was noticeable. In the depth $1200 \mathrm{~mm}$ from the window the $E_{v}$ levels in reference model were $300 \%$ higher and in the depth $1600 \mathrm{~mm}$ even $400 \%$ higher than the $E_{v}$ levels in coloured models. It is obvious, that the colour of surfaces in deeper rooms, especially the colour of floor, may decrease negative effect of excessive depth.

Following diagrams in Fig. 5a-f represent spectral characteristics of indoor daylight for six positions with orientation of sensor towards window and towards side wall. From the courses it is obvious that despite of direct view to window and sky, the coloured surfaces filtered significantly blue dose of daylight in comparison with white model. We can conclude that actual regulation might not provide sufficient evaluation of daylight conditions in terms of biological stimulation. 
a)

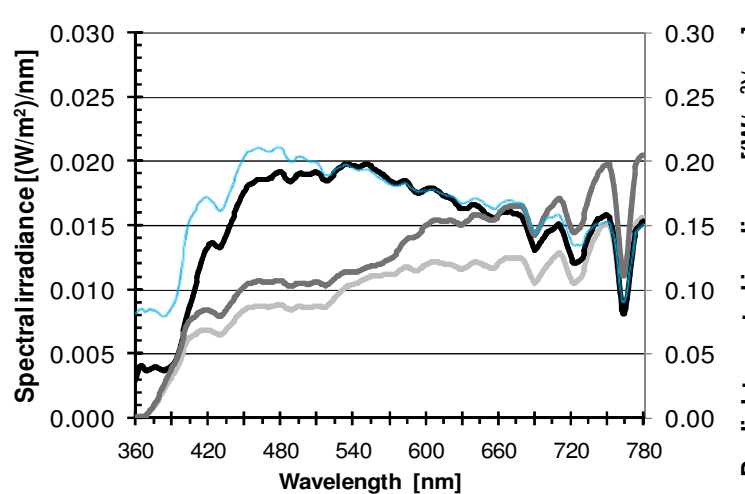

-yellow model $600 \mathrm{~mm}$ to window —white model $600 \mathrm{~mm}$ to window

—orange model $600 \mathrm{~mm}$ to window - daylight in exterior

c)

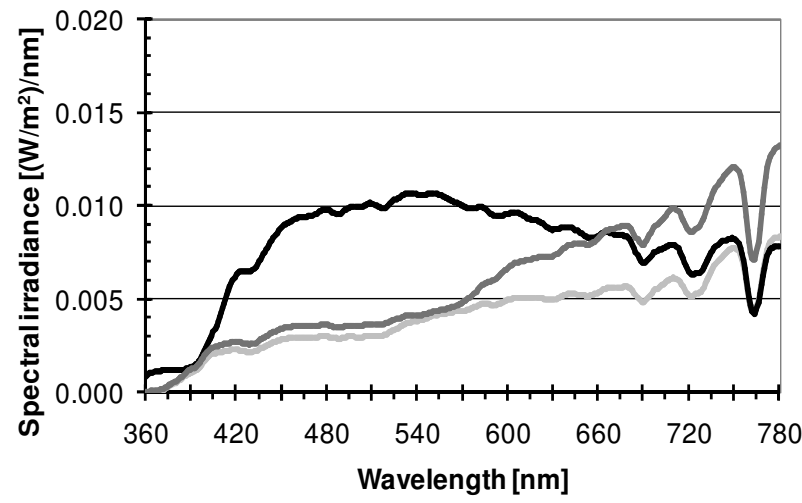

-yellow model $1200 \mathrm{~mm}$ to window —white model $1200 \mathrm{~mm}$ to window —orange model $1200 \mathrm{~mm}$ to window

e)



-yellow model $1600 \mathrm{~mm}$ to window - white model $1600 \mathrm{~mm}$ to window —orange model $1600 \mathrm{~mm}$ to window b)

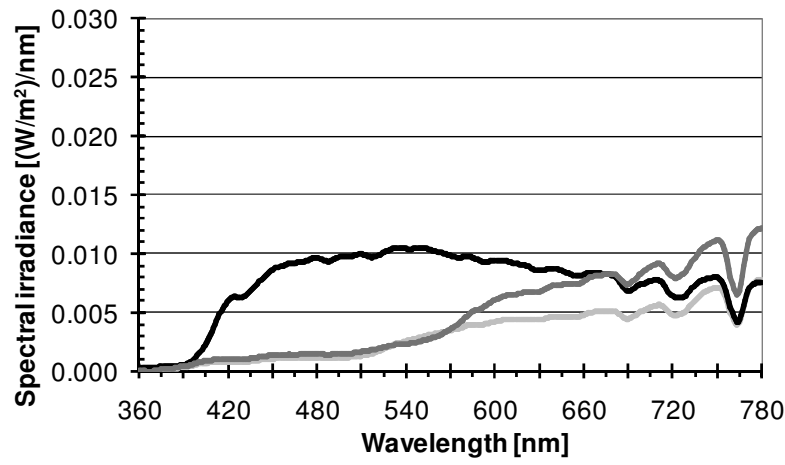

-yellow model $600 \mathrm{~mm}$ to wall —white model $600 \mathrm{~mm}$ to wall —orange model $600 \mathrm{~mm}$ to wall

d)

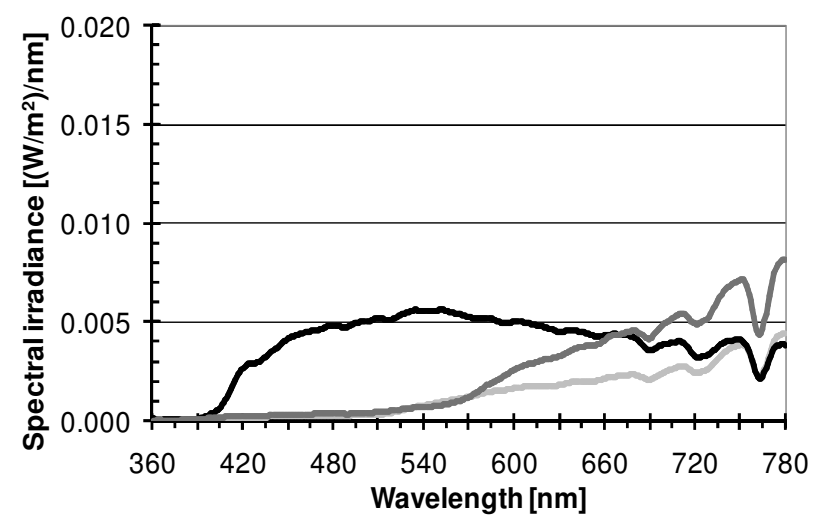

-yellow model $1200 \mathrm{~mm}$ to wall —white model $1200 \mathrm{~mm}$ to wall _orange model $1200 \mathrm{~mm}$ to wall

f)

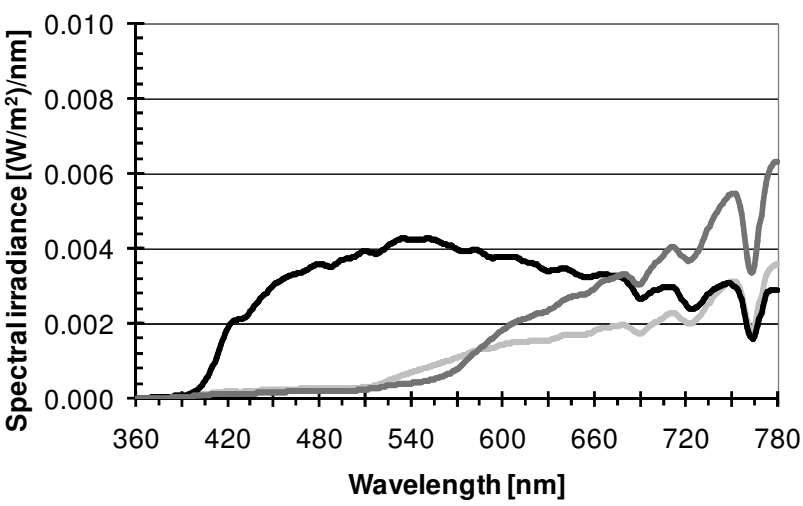

-yellow model $1600 \mathrm{~mm}$ to wall —white model $1600 \mathrm{~mm}$ to wall - orange model $1600 \mathrm{~mm}$ to wall

Fig. 5 (a) Spectral power distribution (SPD) in exterior (right scale), $S P D$ in depth $600 \mathrm{~mm}$ from window directed to window; (b) $S P D$ in 600 $\mathrm{mm}$ from window directed to wall; (c) $S P D$ in $1200 \mathrm{~mm}$ from window directed to window; (d) $S P D$ in $1200 \mathrm{~mm}$ from window directed to wall; (e) $S P D$ in $1600 \mathrm{~mm}$ from window directed to window; (f) $S P D$ in $1600 \mathrm{~mm}$ from window directed to wall.

Table 3. Comparison of external and vertical photopic illuminance levels $E_{v}$ in all models and positions

\begin{tabular}{|c|c|c|c|c|c|c|c|c|c|}
\hline \multirow{2}{*}{$\begin{array}{l}\text { Pos. } \\
\text { from } \\
\text { win. }\end{array}$} & \multirow{5}{*}{$\begin{array}{l}\bar{\Phi} \\
\bar{\delta} \\
\text { है }\end{array}$} & \multicolumn{2}{|c|}{$E_{v}[\mathrm{Ix}]$} & & \multicolumn{2}{|c|}{$E_{V}[\mathrm{~lx}]$} & & \multicolumn{2}{|c|}{$E_{v}[\mathrm{~lx}]$} \\
\hline & & win. & wall & \multirow{4}{*}{$\begin{array}{l}\bar{\Phi} \\
\text { ठ } \\
\text { है }\end{array}$} & win. & wall & \multirow{4}{*}{$\begin{array}{r}\bar{\Phi} \\
\bar{\delta} \\
\text { ठ }\end{array}$} & win. & wall \\
\hline $\begin{array}{l}600 \\
\mathrm{~mm}\end{array}$ & & 782 & 223 & & 1356 & 715 & & 915 & 267 \\
\hline $\begin{array}{c}1200 \\
\mathrm{~mm}\end{array}$ & & 302 & 79 & & 727 & 379 & & 364 & 102 \\
\hline $\begin{array}{c}1600 \\
\mathrm{~mm}\end{array}$ & & 162 & 69 & & 462 & 287 & & 207 & 68 \\
\hline \multicolumn{7}{|c|}{ External photopic illuminance level $E_{v}$} & \multicolumn{3}{|c|}{$26970 \mathrm{Ix}$} \\
\hline
\end{tabular}

Table 4. Comparison of external and vertical normalized circadian light levels $C L_{A}$ in all models and positions

\begin{tabular}{|c|c|c|c|c|c|c|c|c|c|}
\hline \multirow{2}{*}{$\begin{array}{l}\text { Pos. } \\
\text { from } \\
\text { win. }\end{array}$} & & \multicolumn{2}{|c|}{$C L_{A}\left[\mid \mathrm{x}_{C}\right]$} & & \multicolumn{2}{|c|}{$C L_{A}\left[\mid \mathrm{x}_{\mathrm{C}}\right]$} & & \multicolumn{2}{|c|}{$C L_{A}\left[\mathrm{l} \mathrm{x}_{\mathrm{C}}\right]$} \\
\hline & \multirow{3}{*}{$\begin{array}{l}\overline{0} \\
\overline{0} \\
\text { ह }\end{array}$} & win. & wall & \multirow{4}{*}{$\begin{array}{r}\bar{\Phi} \\
\overline{0} \\
\bar{\varepsilon}\end{array}$} & win. & wall & \multirow{4}{*}{\begin{tabular}{|l}
$\bar{\Phi}$ \\
$\overline{0}$ \\
ह
\end{tabular}} & win. & wall \\
\hline $\begin{array}{l}600 \\
\mathrm{~mm}\end{array}$ & & 913 & 145 & & 2194 & 969 & & 1153 & 185 \\
\hline $\begin{array}{c}1200 \\
\mathrm{~mm}\end{array}$ & & 235 & $\sim 0$ & & 1001 & 412 & & 294 & $\sim 0$ \\
\hline $\begin{array}{c}1600 \\
\mathrm{~mm}\end{array}$ & & 85 & $\sim 0$ & & 562 & 279 & & 118 & $\sim 0$ \\
\hline
\end{tabular}


Table 5. Comparison of external and vertical circadian stimulus levels $C S$ in all models and positions

\begin{tabular}{|c|c|c|c|c|c|c|c|c|c|}
\hline \multirow{2}{*}{$\begin{array}{l}\text { Pos. } \\
\text { from } \\
\text { win. }\end{array}$} & \multirow{5}{*}{$\begin{array}{l}\bar{\Phi} \\
\frac{0}{0} \\
\varepsilon\end{array}$} & \multicolumn{2}{|c|}{$C S[-]$} & & \multicolumn{2}{|c|}{$C S[-]$} & & \multicolumn{2}{|c|}{$\operatorname{CS}[-]$} \\
\hline & & win. & wall & \multirow{4}{*}{$\begin{array}{l}\bar{\Phi} \\
\frac{O}{\delta} \\
\varepsilon\end{array}$} & win. & wall & \multirow{4}{*}{$\begin{array}{l}\bar{\Phi} \\
\frac{D}{8} \\
\varepsilon\end{array}$} & win. & wall \\
\hline 600 & & 0.58 & 0.31 & & 0.66 & 0.59 & & 0.61 & 0.3 \\
\hline 1200 & & 0.39 & $\sim 0$ & & 0.59 & 0.47 & & 0.43 & $\sim 0$ \\
\hline 1600 & & 0.23 & $\sim 0$ & & 0.52 & 0.42 & & 0.28 & $\sim 0$ \\
\hline \multicolumn{7}{|c|}{ External circadian stimulus level CS [-] } & \multicolumn{3}{|c|}{0.745} \\
\hline
\end{tabular}

The results in Tab. 6 and Fig. $6 a-f$ provide overview of daylight's colour perception quality influenced by the colour of internal surfaces. When we check the values in position $600 \mathrm{~mm}$ in room depth with orientation towards the lateral wall, the effect of surface colour selection, especially in yellowed model room, is obvious.

Table 6. Comparison of daylight's colour rendering index $C R I, R_{a}$ values in all models and positions

\begin{tabular}{|c|c|c|c|c|c|c|c|c|c|}
\hline \multirow{2}{*}{$\begin{array}{l}\text { Pos. } \\
\text { from } \\
\text { win. }\end{array}$} & \multirow{5}{*}{$\begin{array}{l}\overline{0} \\
\frac{8}{8}\end{array}$} & \multicolumn{2}{|c|}{$R_{a}[-]$} & & \multicolumn{2}{|c|}{$R_{a}[-]$} & & \multicolumn{2}{|c|}{$R_{a}[-]$} \\
\hline & & win. & wall & \multirow{4}{*}{$\begin{array}{l}\overline{\mathcal{D}} \\
\bar{\delta} \\
\mathrm{g}\end{array}$} & win. & wall & \multirow{4}{*}{$\begin{array}{l}\overline{0} \\
\overline{0} \\
\text { ह }\end{array}$} & win. & wall \\
\hline 600 & & 99 & 90 & & 97 & 96 & & 94 & 91 \\
\hline 1200 & & 98 & 87 & & 96 & 94 & & 90 & 89 \\
\hline 1600 & & 98 & 87 & & 95 & 93 & & 87 & 87 \\
\hline \multicolumn{7}{|c|}{ External $R_{a}[-]$} & \multicolumn{3}{|c|}{99} \\
\hline
\end{tabular}

a)

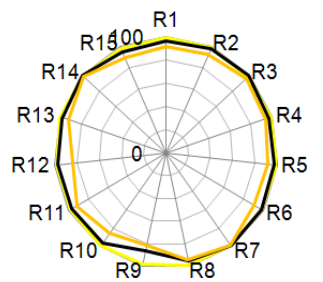

yellow model $600 \mathrm{~mm}$ to window - white model $600 \mathrm{~mm}$ to window

c) - orange model $600 \mathrm{~mm}$ to window



yellow model $1200 \mathrm{~mm}$ to window - white model $1200 \mathrm{~mm}$ to window

e)

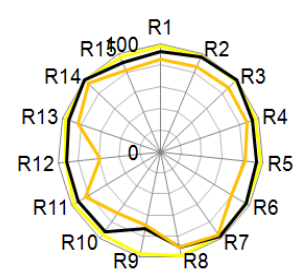

yellow model $1600 \mathrm{~mm}$ to window - white model $1600 \mathrm{~mm}$ to window - orange model $1600 \mathrm{~mm}$ to window b)

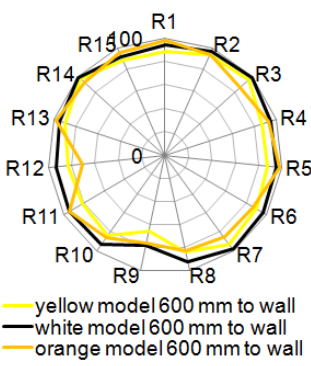

d)

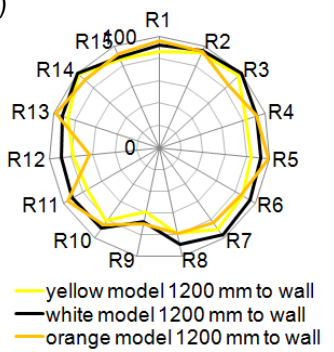

f)

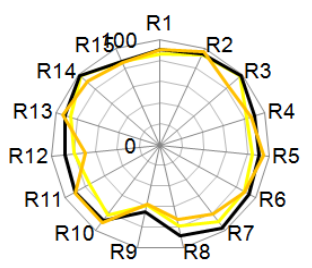

yellow model $1600 \mathrm{~mm}$ to wall - white model $1600 \mathrm{~mm}$ to wall

- orange model $1600 \mathrm{~mm}$ to wall
Fig. 6. Results of R1-R15 levels in positions oriented-towards window and towards lateral wall in $600 \mathrm{~mm}(\mathrm{a}-\mathrm{b}), 1200 \mathrm{~mm}(\mathrm{c}-\mathrm{d})$ and $1600 \mathrm{~mm}(\mathrm{e}-\mathrm{f})$

\section{Conclusion}

This experiment showed possible negative consequences of internal surface colour selection for permanently occupied spaces, especially in deep office rooms. The measurement of horizontal photopic illuminance emphasised the effect of dark flooring in deep room, when reference model provided 3 times higher $E_{v}$ levels in 1200 $\mathrm{mm}$ and almost 4 times higher $E_{v}$ in depth of 1600 from window. The biological aspect of measurement provided potentially very negative influence of yellow and orange surface colour in bigger distances from window. Diagrams of $S P D$ in Fig. $5 a-f$ represent the continual decrease of blue dose of light in models with coloured surfaces, which is the most important for our biological stimulation. According computational program developed by Rea [4], the distance of $1200 \mathrm{~mm}$ and $1600 \mathrm{~mm}$ from window with sensor orientation towards the wall provided biological stimulation close to zero. This is showed in Tab. 4 and 5 , where $C L_{A}$ levels in deep spaces are close to zero level because of filtration of blue dose of light by yellow and orange colour. Models with yellow and orange walls provided 6 times lower $C L_{A}$ values in position $600 \mathrm{~mm}$ from the window and orientation into wall than the same position with orientation towards the window. On the other hand reference model provided almost $50 \%$ difference in the same comparison. There is also noticeable difference in CS level in room depth of $600 \mathrm{~mm}$ with the orientation of sensor towards window and towards lateral wall. The difference between these orientations for coloured models is almost $50 \%$ whereas reference model provided distinction close to 10 $\%$. So, the same illuminance levels on horizontal plane may provide significant differences in spectral characteristics on vertical plane, which is important for biological stimulation. The evaluation of $C R I$ represented by $R_{a}$ confirms noticeable influence on colour perception. Colour perception is related to spatial perception and can influence interior occupant's performance, especially on psychological aspects.

\section{Acknowledgements}

This article was supported by Slovak Research and Development Agency under the contract No. APVV 015010, APVV 0118-12 and project VEGA 1/0286/15

\section{REFERENCES}

[1] Bellia, L.Seraceni, M.: A proposal for a simplified model to evaluate the circadian effects of light sources. Lighting Research and Technology, 46(5), (2013), 493-505. doi:

$10.1177 / 1477153513490715$

[2] Berson, D. M., Dunn, F. A.Takao, M.: Phototransduction by retinal ganglion cells that set the circadian clock. Science, 295(5557), (2002), 1070-1073. doi: 10.1126/science.1067262 [3] Hattar, S., Liao, H. W., Takao, M., Berson, D. M.Yau, K. W.: Melanopsin-containing retinal ganglion cells: architecture, projections, and intrinsic photosensitivity. Science, 295(5557), (2002), 1065-1070. doi: 10.1126/science.1069609

[4] Rea, M. S., Figueiro, M. G., Bierman, A.Bullough, J. D.: Circadian light. J. Circadian Rhythms, 8(1), 2, (2010). doi: 10.1186/1740-3391-8-2

[5] Bellia, L., Pedace, A.Barbato, G.: Indoor artificial lighting: Prediction of the circadian effects of different spectral power distributions. Lighting Research and Technology, 46(6), (2013), 650-660. doi: 10.1177/1477153513495867

[6] Rea, M. S., Bierman, A., Figueiro, M. G.Bullough, J. D.: A new approach to understanding the impact of circadian disruption on human health. J Circadian Rhythms, 6, 7. (2008), doi:

10.1186/1740-3391-6-7 